\title{
Mathematics everywhere
}

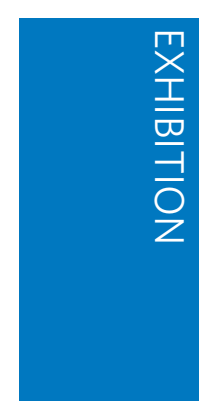

Winton Gallery, is not about the aesthetics, but the usefulness of mathematics and how it underlies almost every aspect of modern life.

The exhibition is a tribute to applied mathematics. This is made very clear by the design of the gallery, created by Zaha Hadid Architects and inspired by the turbulent air flow around aircraft wings (pictured). The centre piece is the 1929 Gugnunc aircraft and the visitor travels along the lines of the airflow, translated into the physical space by the stunning architecture. Along these lines one finds more than 100 historical objects grouped in six different themes: trade and travel, maps and models, war and peace, form and beauty, life and death, and money.

There is a very good reason for focusing on the uses of mathematics in everyday life, on how, according to curator David Rooney, it is "at the heart of everything you care about". Let's face it: most people are afraid of maths. It feels alien and impossible to understand. To fight the unavoidable anxiety such a visitor would face entering the gallery, the Science Museum decided to emphasize how mathematics underpins the modern world through a varied selection of exhibits. Ship models used in experimental fluid dynamics feature, along with the 1935 differential analyser used at Manchester University
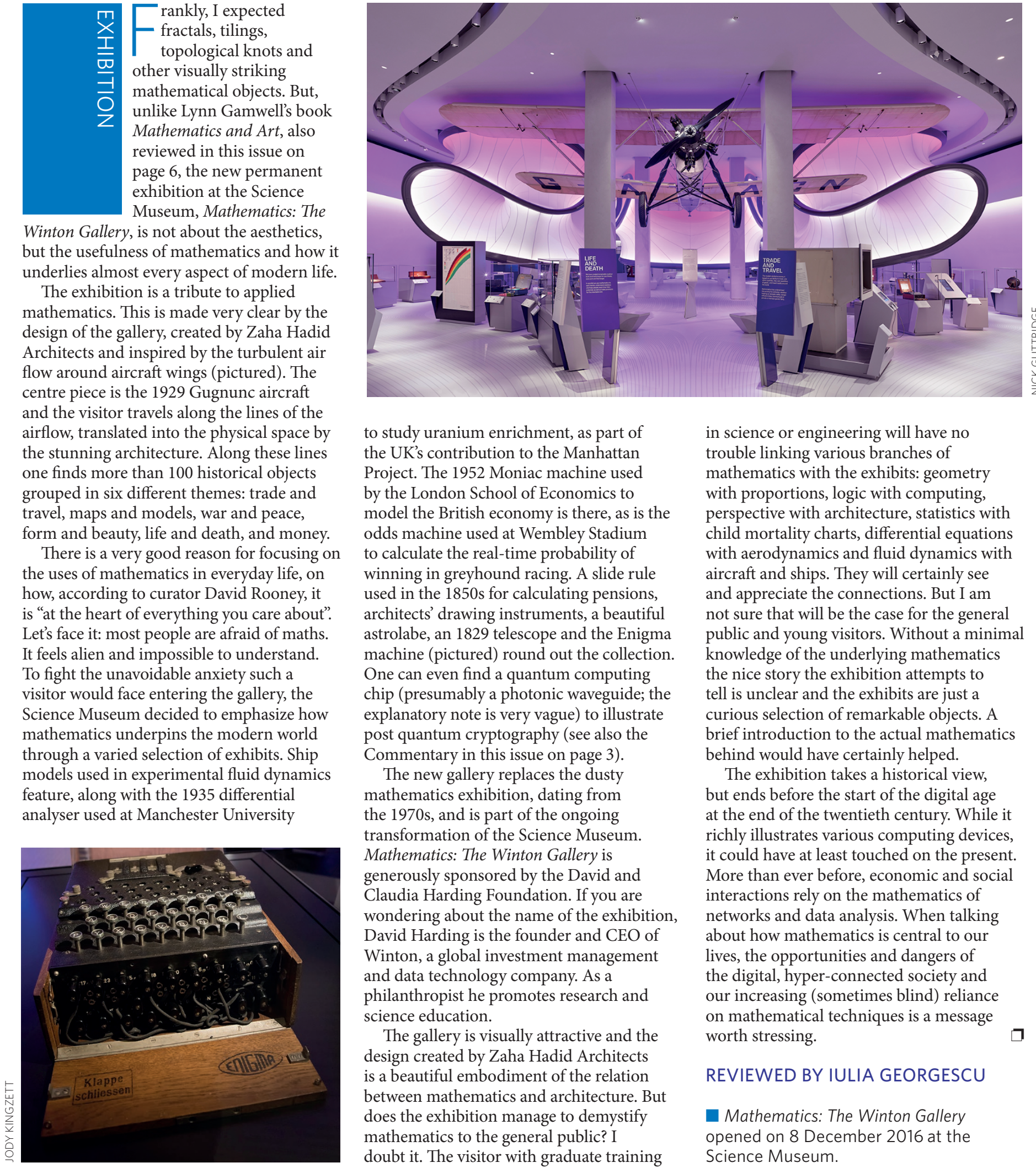

to study uranium enrichment, as part of the UK's contribution to the Manhattan Project. The 1952 Moniac machine used by the London School of Economics to model the British economy is there, as is the odds machine used at Wembley Stadium to calculate the real-time probability of winning in greyhound racing. A slide rule used in the 1850s for calculating pensions, architects' drawing instruments, a beautiful astrolabe, an 1829 telescope and the Enigma machine (pictured) round out the collection. One can even find a quantum computing chip (presumably a photonic waveguide; the explanatory note is very vague) to illustrate post quantum cryptography (see also the Commentary in this issue on page 3 ).

The new gallery replaces the dusty mathematics exhibition, dating from the 1970s, and is part of the ongoing transformation of the Science Museum. Mathematics: The Winton Gallery is generously sponsored by the David and Claudia Harding Foundation. If you are wondering about the name of the exhibition, David Harding is the founder and CEO of Winton, a global investment management and data technology company. As a philanthropist he promotes research and science education.

The gallery is visually attractive and the design created by Zaha Hadid Architects is a beautiful embodiment of the relation between mathematics and architecture. But does the exhibition manage to demystify mathematics to the general public? I doubt it. The visitor with graduate training in science or engineering will have no trouble linking various branches of mathematics with the exhibits: geometry with proportions, logic with computing, perspective with architecture, statistics with child mortality charts, differential equations with aerodynamics and fluid dynamics with aircraft and ships. They will certainly see and appreciate the connections. But I am not sure that will be the case for the general public and young visitors. Without a minimal knowledge of the underlying mathematics the nice story the exhibition attempts to tell is unclear and the exhibits are just a curious selection of remarkable objects. A brief introduction to the actual mathematics behind would have certainly helped.

The exhibition takes a historical view, but ends before the start of the digital age at the end of the twentieth century. While it richly illustrates various computing devices, it could have at least touched on the present. More than ever before, economic and social interactions rely on the mathematics of networks and data analysis. When talking about how mathematics is central to our lives, the opportunities and dangers of the digital, hyper-connected society and our increasing (sometimes blind) reliance on mathematical techniques is a message worth stressing.

\section{REVIEWED BY IULIA GEORGESCU}

Mathematics: The Winton Gallery opened on 8 December 2016 at the Science Museum. 